\title{
Cold Plasma Deposition of Polymeric Nanoprotrusion, Nanoparticles, and Nanofilm Structures on a Slide Glass Surface
}

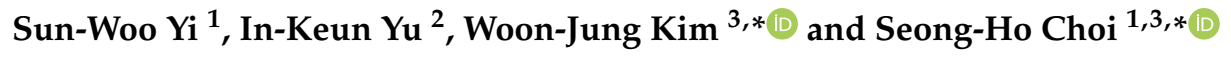 \\ 1 Department of Cosmetic Science, Hannam University, Daejeon 34054, Korea; naalto@naver.com \\ 2 Plasma Technology Research Institute, Korea Institute of Fusion Energy (KFE) , Gunsan 54004, Korea; \\ ikyu@kfe.re.kr \\ 3 Department of Chemistry, Hannam University, Daejeon 34054, Korea \\ * Correspondence: wjkim@hnu.kr (W.-J.K.); shchoi@hnu.kr (S.-H.C.); Tel.: +82-42-629-8824 (S.-H.C.)
}

Citation: Yi, S.-W.; Yu, I.-K.; Kim, W.-J.; Choi, S.-H. Cold Plasma

Deposition of Polymeric

Nanoprotrusion, Nanoparticles, and Nanofilm Structures on a Slide Glass Surface. Processes 2021, 9, 99. https://doi.org/10.3390/pr9010099

Received: 28 November 2020

Accepted: 4 January 2021

Published: 5 January 2021

Publisher's Note: MDPI stays neutral with regard to jurisdictional clai$\mathrm{ms}$ in published maps and institutional affiliations.

Copyright: $\odot 2021$ by the authors. Licensee MDPI, Basel, Switzerland. This article is an open access article distributed under the terms and conditions of the Creative Commons Attribution (CC BY) license (https:// creativecommons.org/licenses/by/ $4.0 /)$.

\begin{abstract}
In this study, we coated the surface of glass slides with nanoprotrusion, nanoparticles, and nanofilm structures by one-step plasma deposition of three vinyl monomers. Three functional vinyl monomers with symmetrical polarity sites were used: methyl methacrylate (MMA), trifluoro methylmethacrylate (TFMA), and trimethylsilyl methyl methacrylate (TSMA). The TSMA/MMA (80/20, mol-\%) nanoprotrusion-coated surface of slide glass was superhydrophobic, with a $153^{\circ}$ contact angle. We also evaluated the transmittance (\%) of the slide glass with nanoprotrusions in the infrared (IR) $(940 \mathrm{~nm})$, ultraviolet $(365 \mathrm{~nm})$ and visible light $(380-700 \mathrm{~nm})$ regions. The obtained nanoprotrusion structure surface of slide glass created by plasma deposition transmits more than $90 \%$ of visible light.
\end{abstract}

Keywords: plasma process; methyl methacrylate (MMA); trifluoro methylmethacrylate (TFMA); trimethylsilyl methyl methacrylate (TSMA); nanoprotrusion structure; nanoparticles structure; nanofilm structure; super hydrophobic properties

\section{Introduction}

Materials with superhydrophobic properties are in extremely high demand because they have various potential applications, which include anti-corrosion coatings, microfluidic devices, oil/water separation, anti-icing coatings, nanoparticle assembly, liquidrepellent textiles, printing techniques, optical devices, highly sensitive sensors and batteries [1-8]. In many of these applications, having a layer of air trapped inside a rough surface can reduce liquid penetration (oil/water separation, anti-fogging), ion penetration (anti-corrosion, water desalination, batteries), or heat transfer (anti-icing), while surface roughness can improve the inherent properties of a material (electrical, optical, and catalytic properties). It is also very important that the superhydrophobic coating is robust, which means that the materials maintain their properties even under high pressures. A relatively simple way to create these properties is to imitate nature to create synthetic materials.

In addition, cold plasma deposition has recently received a lot of attention for its ability to grow plasma-polymer films on different substrates [9-11]. In previous papers, we successfully prepared a metal-polymer catalytic electrode by a cold plasma process in the presence of acrylic acid as a binder [12]. The prepared metal-polymer catalytic electrode was characterized by Fourier transform infrared (FT-IR) spectroscopy, scanning electron microscopy (SEM), contact angle, X-ray photoelectron spectroscopy (XPS) and energy-dispersive X-ray spectroscopy (EDS). The results indicate that vinyl monomers are easily and simply polymerized on the surface during the cold plasma process.

In the realm of functional materials, superhydrophobic coatings are often used to produce clear screens and anti-fingerprint effects in display fields such as mobile phones 
and TVs. Since such coatings are expected to have cleaning and anti-corrosion effects hydrophobic surfaces are being developed in various fields.

In this study, we coated slide glass surfaces with vinyl polymers with nanoprotrusion structures via cold plasma deposition to obtain superhydrophobic properties. We used three functional vinyl monomers, methyl methacrylate (MMA), trifluoro methylmethacrylate (TFMA), and trimethylsilyl methyl methacrylate (TSMA), in various mixtures. The fabricated polymer-coated slide glasses were evaluated for water contact angle, morphology via SEM, and transmittance in the infrared (IR) $(940 \mathrm{~nm})$, ultraviolet $(365 \mathrm{~nm})$ and visible light (380-700 $\mathrm{nm}$ ) regions. Given the results, we discuss the the superhydrophobic properties of plasma-polymer coated slide glass with nanoprotrusions.

\section{Materials and Methods}

\subsection{Reagents}

We purchased MMA, TFMA, and TSMA from Sigma Aldrich Co. Slide glass $(76 \times 26 \times 1.0 \mathrm{~mm})$ as a substrate was obtained from Matsunami Co., Ltd., Osaka, Japan. Before plasma coating, we washed the substrate three times using water, methanol and acetone solvents sequentially.

\subsection{Instrumentation}

We characterized the surface properties with contact angle measurements (PHOENIX 300, Surface Electro Optics Co., Ltd., Gyeonggi-do, Korea), scanning electron microscopy (FE-SEM, S 4800, Hitachi, Tokyo, Japan), X-ray photoelectron spectroscopy (XPS, K-alpha, Thermo Scientific Inc., Waltham, MA, USA) and a spectrum transmission meter (LS183, Shenzhen Linshang Technology Co., Ltd., Shenzhen, China).

Plasma devices have to be small, simple, and portable to be useful in a wide variety of applications. We chose a cold plasma device that meets these requirements [12]. The plasma equipment was directly obtained from Applied Plasma Inc. (model 3D+iCVC SINGLE) at Gumi City, Korea. The plasma equipment has voltage of input $220 \mathrm{~V}$ and output $15 \mathrm{KV}$ rms, amphare with input $5 \mathrm{~A}$ and output $70 \mathrm{~mA}$, frequency with input $60 \mathrm{~Hz}$ and output $30-40 \mathrm{KHz}$, phase with input single and output single, and air pressure with input $0.5 \mathrm{Mpa}$ and output $0.025 \mathrm{Mpa}$, respectively. The device's power can be controlled in the range of 200 to $250 \mathrm{~W}$. Most experiments were conducted at approximately $200 \mathrm{~W}$. The torch used in this experiment was conical and the diameter of the torch tip was $2.0 \mathrm{~mm}$. Nitrogen was supplied as a working gas in a tank connected to the plasma generator, with a flow controller inside. The plasma generator was used to maintain a constant pressure level. Polymer stock solution was injected into the cold plasma jet by a syringe pump in the downstream region. The slide glass substrate was placed under the cold plasma jet at a distance of $1 \mathrm{~cm}$ and manually moved during the deposition process.

\subsection{Plasma Coating of the Slide Glass Surface}

Figure 1 schematically illustrates the process of poly(TFMA-co-MMA) deposition on the slide glass surface; the formation of dipole moments was prevented by symmetric polarity in the plasma polymerization process. First, the coating solution was prepared by mixing of MMA, TFMA and TSMA according to the experimental conditions. Plasma polymerization was accomplished by injection of a solution through a syringe pump at $0.1 \mathrm{~mL} / \mathrm{s}$ for a total amount of $5.0 \mathrm{~mL}$ using cold plasma equipment [12]. 
<smiles>C=C(C)C(=O)C(F)(F)F</smiles>

TFMA<smiles>C=C(C)C(=O)[CH][18OH]</smiles>

MMA

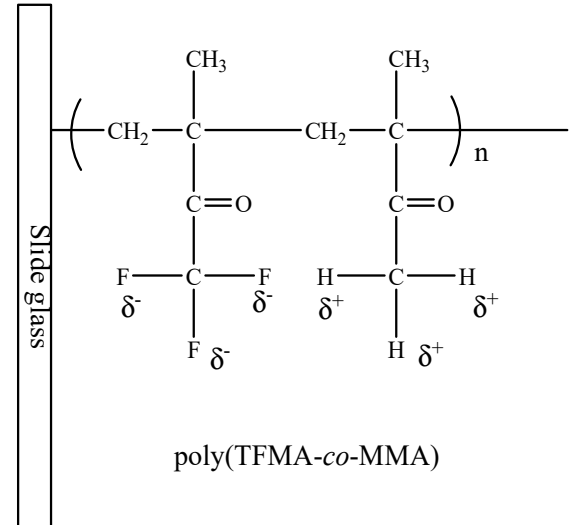

Figure 1. Schematic illustration of formation of a poly(TFMA-co-MMA) coating on the surface of a glass slide by plasma polymerization.

\section{Results}

\subsection{Plasma Polymerization of Poly(TFMA-co-MMA) on the Slide Glass Surface}

Table 1 shows the results of measuring the water contact angles $\left(^{\circ}\right)$ and transmittance $(\%)$ of the plasma-coated polymer-coated slide glass three times according to the molar ratio of TFMA/MMA. The water contact angle $\left(^{\circ}\right)$ of the untreated slide glass surface was $18.5^{\circ}$, and the transmittance (\%) was 99\% for ultraviolet (UV) at $365 \mathrm{~nm}$, IR at $940 \mathrm{~nm}$, and visible light (VL) from 380-700 nm. After plasma polymerization, the water contact angle increased because of the increased hydrophobicity of the coated poly(TFMA-co-MMA) surface.

Table 1. Physical properties of glass slides plasma-coated with poly(TFMA-co-MMA) coatings.

\begin{tabular}{|c|c|c|c|c|c|}
\hline \multirow{2}{*}{ Exp. No } & \multirow{2}{*}{ TFMA/MMA (mol-\%) } & \multirow{2}{*}{ Contact Angle $\left(^{\circ}\right)$} & \multicolumn{3}{|c|}{ Transmittance (\%) } \\
\hline & & & UV (365 nm) & IR (940 nm) & VL $(380 \mathrm{~nm} \sim 700 \mathrm{~nm})$ \\
\hline 1 & $100 / 0$ & $51.0^{\circ}$ & 91.0 & 89.1 & 92.3 \\
\hline 2 & $80 / 20$ & $56.6^{\circ}$ & 91.3 & 88.6 & 92.8 \\
\hline 3 & $60 / 40$ & $78.2^{\circ}$ & 91.4 & 88.7 & 92.8 \\
\hline 4 & $40 / 60$ & $40.1^{\circ}$ & 93.4 & 89.3 & 92.7 \\
\hline 5 & $20 / 80$ & $34.7^{\circ}$ & 93.0 & 89.1 & 92.5 \\
\hline 6 & $0 / 100$ & $42.6^{\circ}$ & 91.3 & 88.4 & 90.6 \\
\hline 7 & Glass surface & $18.5^{\circ}$ & 99.0 & 99.0 & 99.0 \\
\hline
\end{tabular}

Figure 2 shows water contact angle images of the slide glass surfaces coated with poly(TFMA-co-MMA) prepared by plasma polymerization. The vinyl monomers TFMA and MMA were selected because the vinyl group can induce formation of free radicals which then polymerize; also, the side groups containing trifluromethyl and methyl groups have symmetrical polarity, as shown in Figure 1. The hydrophobic properties of the coated poly(TFMA-co-MMA) could result from low dipole moment-induced symmetrical polarity.

Figure 3 shows SEM images of the plasma-coated glass surfaces and side faces of the first two specimens (TFMA-co-MMA, No. 1 and 2 in Table 1). The coated poly(TFMA) specimen showed an amorphous morphology, as film structure; it is No. 1 in Table 1. Small polymer islands of poly(TFMA) were found on the surface of the slide glass surface. In the side face SEM image of the poly(TFMA)-coated slide glass, the poly(TFMA) coating appeared to be thin due to low polymerization yields during the plasma process. The surface morphology of poly(TFMA-co-MMA, 80/20 mol-\%) also appeared to be amorphous, with some aggregation, as shown in surface SEM image No. 2. The film thickness of poly(TFMA-co-MMA) was dramatically increased compared to that of poly(TFMA) (No. 2 in Figure 3). 
$51.0^{\circ}$

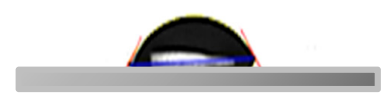

No. 1

$40.1^{\circ}$ $56.6^{\circ}$

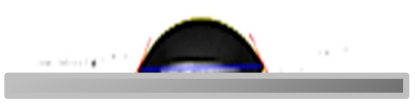

No. 2 $78.2^{\circ}$

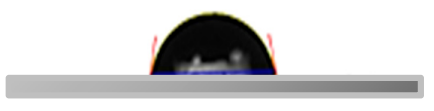

No. 3

$42.6^{\circ}$

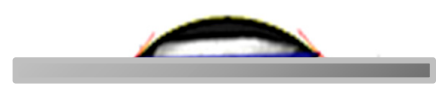

No. 4

$18.5^{\circ}$

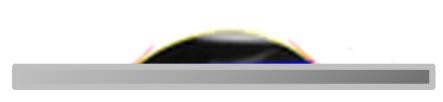

No. 5
No. 6

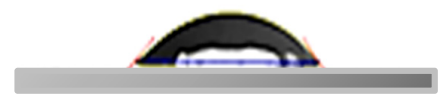

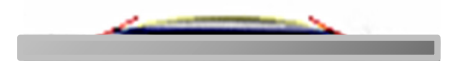

No. 7

Figure 2. Water contact angle images of the slide glass surface with poly(TFMA-co-MMA) coated by plasma polymerization.
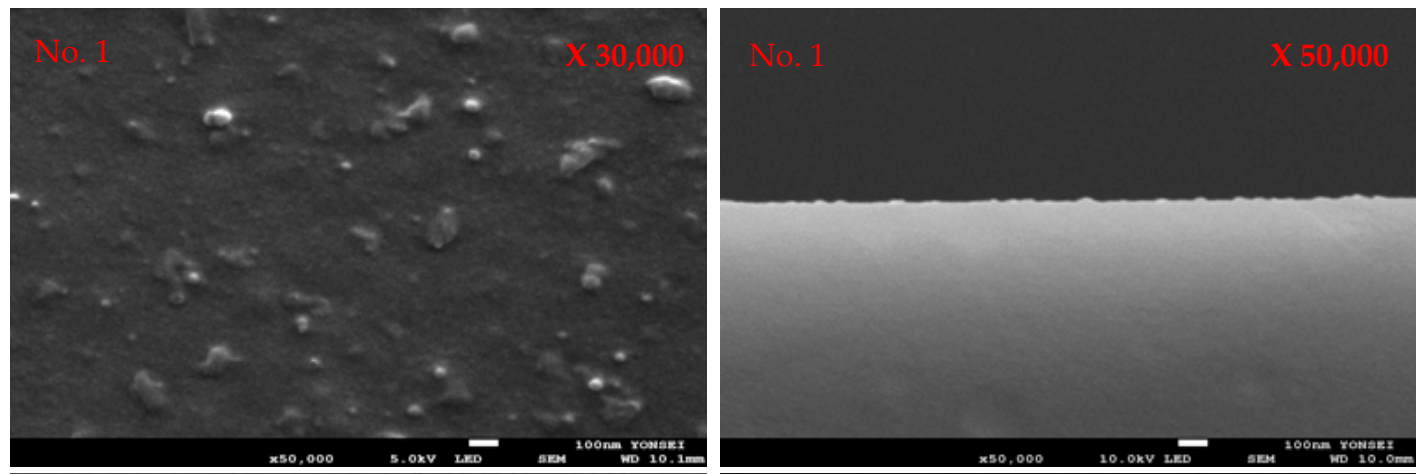

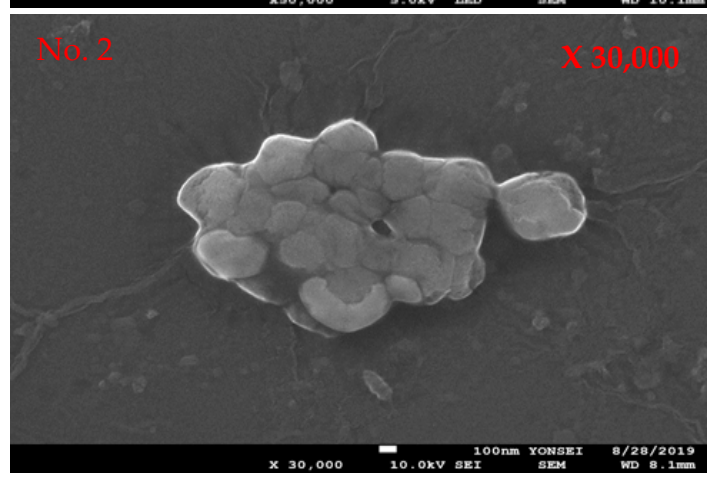

Surface

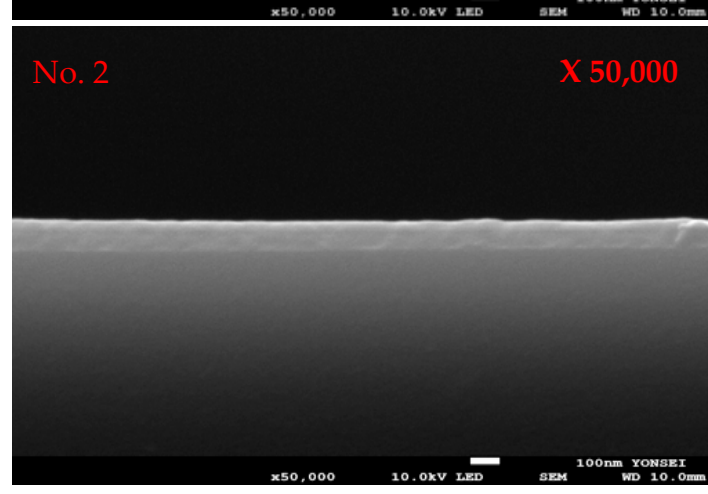

Side face

Figure 3. Scanning electron microscope (SEM) images of plasma-coated glass surfaces and side faces (TFMA-co-MMA, No. 1 and 2 in Table 1). 
Figure 4 shows SEM images of the plasma-coated glass surfaces and side faces of the third and fourth specimens (TFMA-co-MMA, No. 3 and 4 in Table 1). The surface morphology of poly(TFMA-co-MMA, No. 3 and No. 4 in Table 1) also appeared to be amorphous. The surface SEM image of No. 3 showed aggregation, while the aggregates disappeared above a mol ratio of $60 \%$ with the addition of MMA. The film thickness of poly(TFMA-coMMA) was dramatically increased on the surface of the slide glass. When the amount of MMA increased in poly(TFMA-co-MMA), the polymer aggregates disappeared.
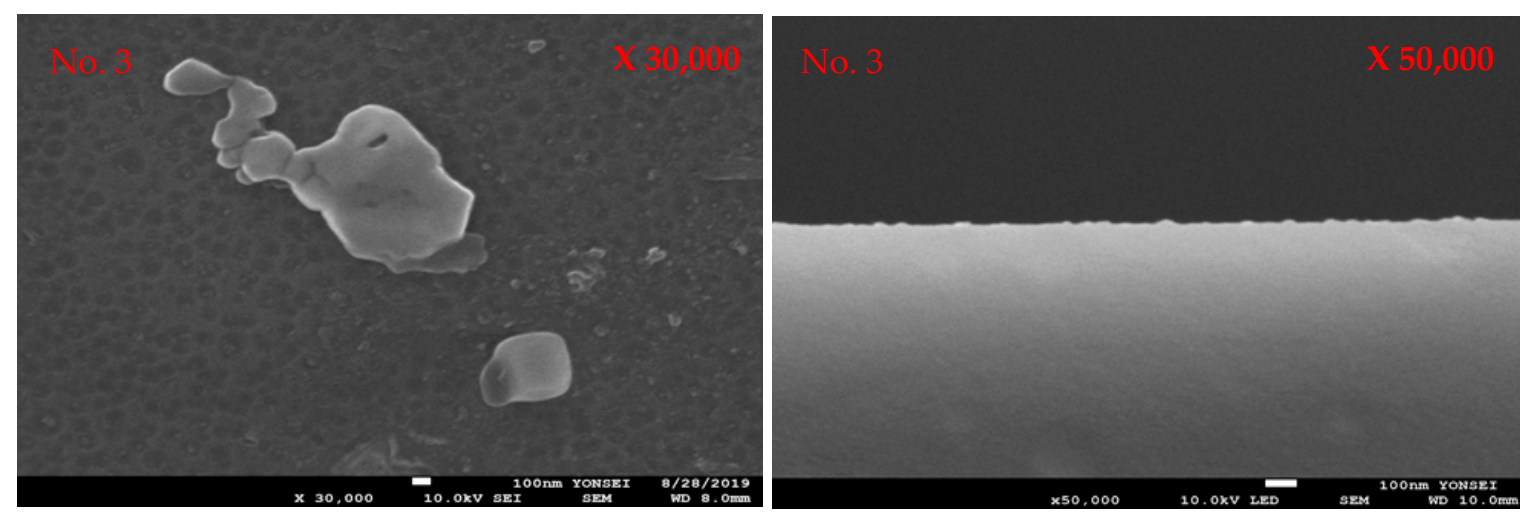

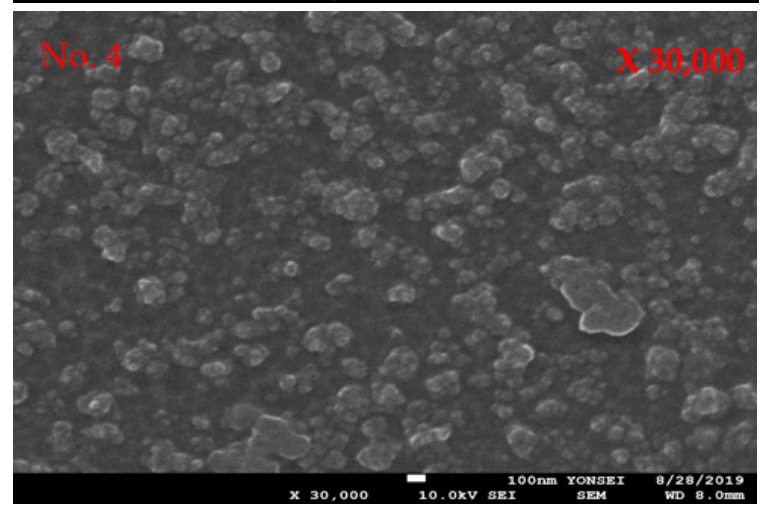

Surface

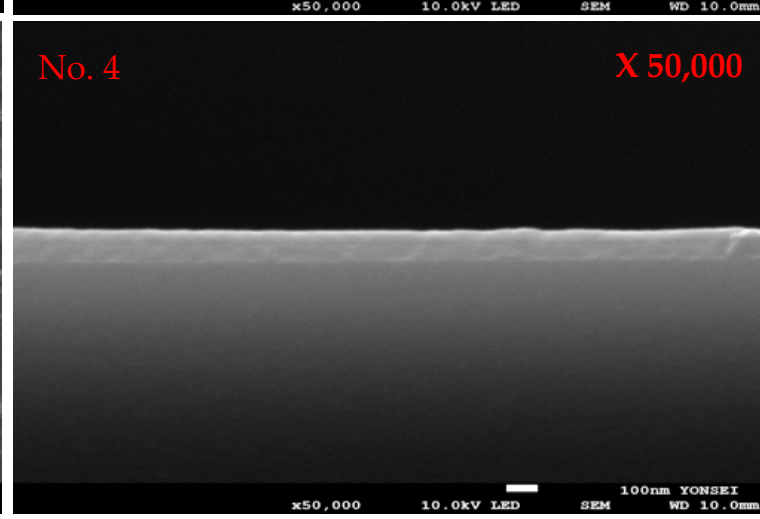

Side face

Figure 4. SEM images of plasma-coated glass surfaces and side faces (TFMA-co-MMA, No. 3 and 4 in Table 1).

Figure 5 shows SEM images of the fifth and sixth plasma-coated glass surfaces and side faces (TFMA-co-MMA, No. 5 and 6 in Table 1). When a great deal of MMA was added to the feed solution, no aggregated polymeric particles were present, while amorphous film-type polymers were coated on the surface of the slide glass, as shown in Figure 5. On the poly(MMA)-coated surface, an amorphous film surface was observed. These results show that plasma polymerization is an easy means of surface modification to produce special functional properties. However, we could not create a superhydrophobic surface by plasma copolymerization of the TFMA/MMA feed solution.

In order to confirm successful coating of poly (TFMA-co-MMA, No. 3) which had the highest water contact angle, we performed XPS analysis. Figure 6 shows the XPS spectra of the slide glass surface coated with poly(TFMA-co-MMA), No. 3 in Table 1, prepared by plasma polymerization. A fluorine peak was observed at $\sim 690 \mathrm{eV}$, which is ascribed to poly(TFMA). Given these results, we can conclude that plasma polymerization is an easy and simple mechanism of surface modification of functional vinyl monomers on the surface of glass slides. 

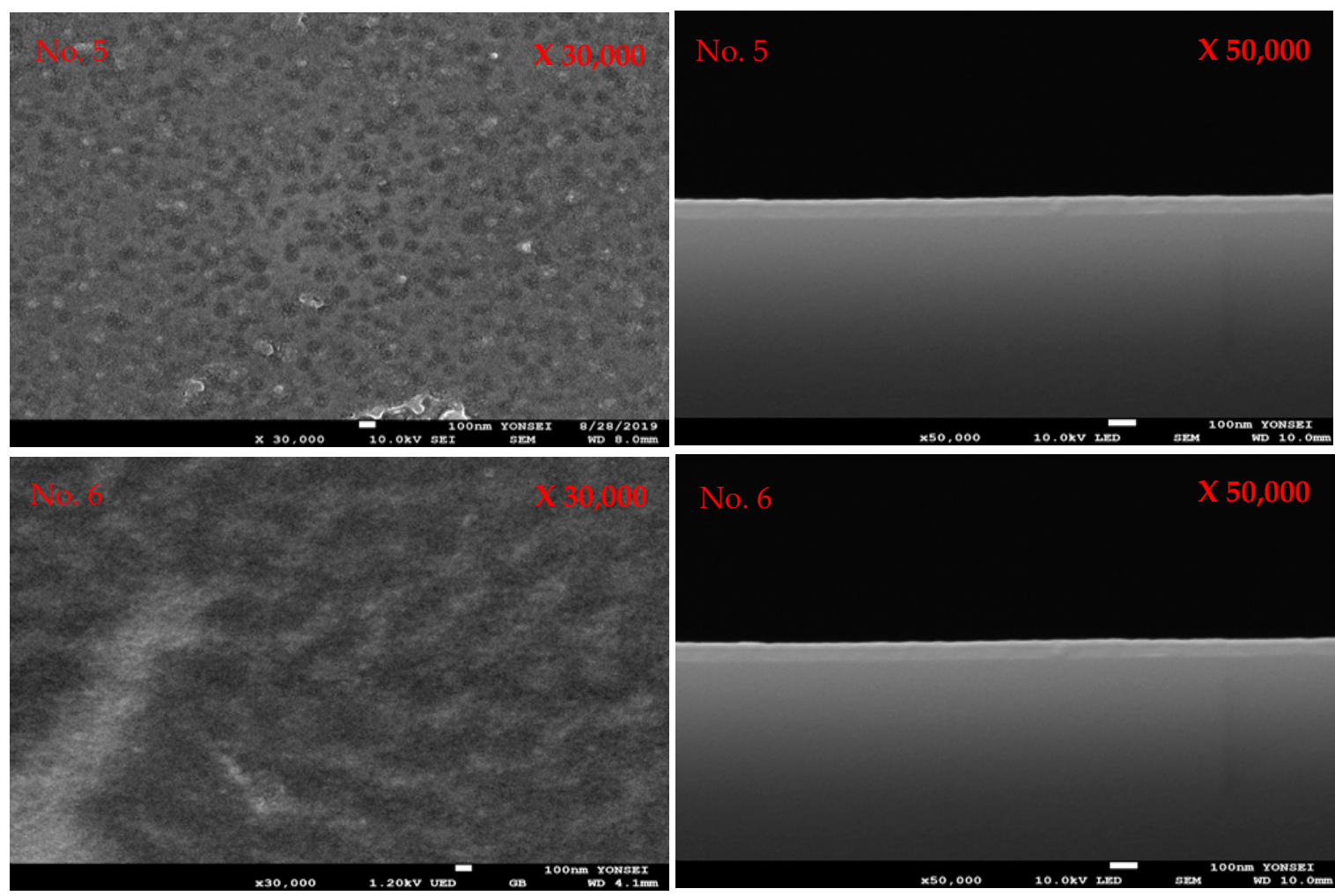

Surface

Side face

Figure 5. SEM images of glass surfaces and side faces plasma-coated with poly(TFMA-co-MMA, No. 5 and 6 in Table 1).

\begin{tabular}{cc}
\hline Name & Atomic \% \\
\hline C1s & 68.77 \\
F1s & 3.78 \\
O1s & 24.75 \\
Si2p & 1.70 \\
\hline
\end{tabular}

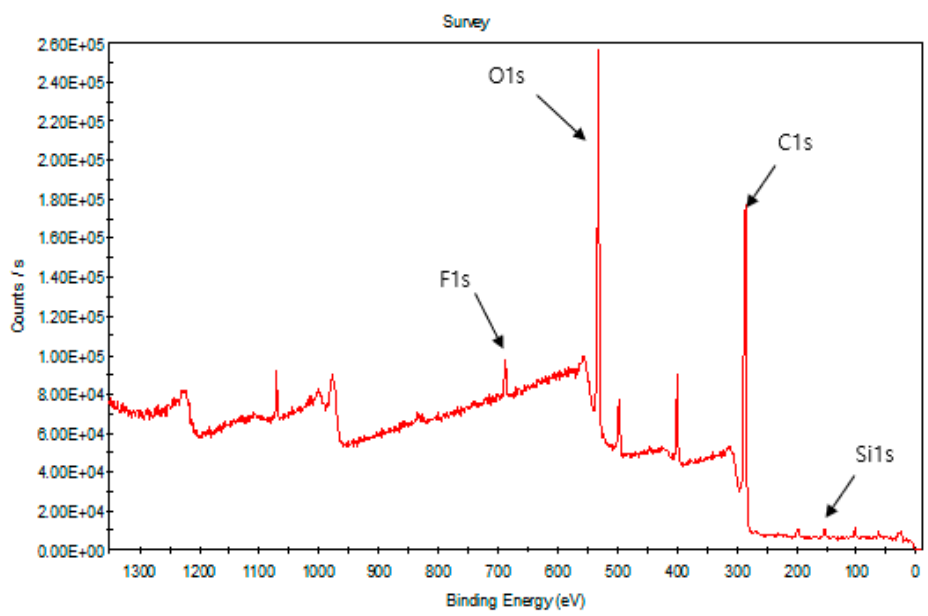

Figure 6. X-ray photoelectron spectroscopy (XPS) spectra of glass slides plasma-coated with poly(TFMA-co-MMA) (No. 3 in Table 1).

\subsection{Plasma Polymerization of Poly(TSMA-co-MMA) on a Slide Glass Surface}

In order to obtain superhydrophobic properties, we selected two vinyl monomers with polar side groups, TSMA and MMA. Figure 7 shows a schematic illustration of poly(TSMAco-MMA) deposition on the glass slide surface by plasma polymerization. We expected that the specimen would be superhydrophobic due to a lack of dipole moments from the sum of symmetric polarity. Also, we think hydrophobicity is rather expected because of $-\mathrm{CH}_{3}$ groups, which are known for their capacity to induce hydrophobicity. 
<smiles>C=C(C)C(=O)[Si](C)(C)C</smiles>

TSMA<smiles>C=C(C)C(=O)[CH][18OH]</smiles>

MMA

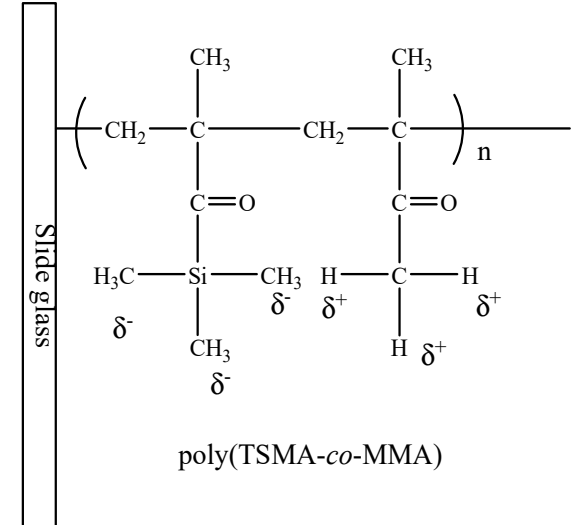

Figure 7. Schematic illustration of poly(TSMA-co-MMA) coating of a glass slide surface. There is an absence of dipole moments due to symmetric polarity during plasma polymerization.

Table 2 represents the physical properties of the glass slide coated with poly(TSMA-coMMA) by plasma polymerization. The water contact angle of TSMA/MMA at 80/20 mol-\% was $153^{\circ}$ representing its superhydrophobicity. The transmittance (\%) in the UV (365 nm), IR (940 nm), and VL (380-700 nm) regions was very high, as shown in Table 2. When we compared the transmittance of the poly(TFMA-co-MMA)- and poly(TSMA-co-MMA)coated glass slides, the transmittance of the poly(TSMA-co-MMA)-coated slide was less than that of the poly(TFMA-co-MMA)-coated slide because of the $\mathrm{Si}\left(\mathrm{CH}_{3}\right)$ group, which is an inorganic element with lower transmittance [13].

Table 2. Physical properties of glass slides with poly(TSMA-co-MMA) coatings prepared by plasma polymerization.

\begin{tabular}{|c|c|c|c|c|c|}
\hline \multirow{2}{*}{ Exp. No. } & \multirow{2}{*}{ TSMA/MMA (mol-\%) } & \multirow{2}{*}{ Contact Angle ( ${ }^{\circ}$ ) } & \multicolumn{3}{|c|}{ Transmittance (\%) } \\
\hline & & & UV (365 nm) & IR $(940 \mathrm{~nm})$ & VL $(380 \sim 700 \mathrm{~nm})$ \\
\hline 1 & $100 / 0$ & 110 & 58.4 & 87.9 & 84.1 \\
\hline 2 & $80 / 20$ & 153 & 77.1 & 90.0 & 85.0 \\
\hline 3 & $60 / 40$ & 123 & 69.3 & 88.7 & 88.2 \\
\hline 4 & $40 / 60$ & 115 & 55.5 & 89.7 & 84.2 \\
\hline 5 & $20 / 80$ & 95.0 & 54.4 & 86.9 & 84.1 \\
\hline
\end{tabular}

Figure 8 shows water contact angle images of the slide glass surfaces coated with poly(TSMA-co-MMA) prepared by plasma polymerization. It is evident that the surface coated with poly(TSMA-co-MMA) at 80/20 mol- $\%$ was superhydrophobic, with a water contact angle of $153^{\circ}$. The water contact angles of the poly(TSMA-co-MMA)-coated slide was greater than that of the poly(TFMA-co-MMA)-coated slide because of the nanostructure of the coated polymers.

Figure 9 shows SEM images of the plasma-coated glass surface and side face of poly(TSMA-co-MMA (No. 1 and No. 2 in Table 2). The nanoprotrusion structure of the poly(TSMA) on the surface of the slide is shown in No. 1 in Figure 9. In the poly(TSMAco-MMA, 80/20 mol-\%) specimen, a nanoprotrusion structure formed on the surface of the slide glass, as shown in No. 2 in Figure 9. These nanoprotrusions contribute to the superhydrophobic properties of the specimen.

Figure 10 shows SEM images of the plasma-coated glass surfaces and side faces of poly(TSMA-co-MMA) (No. 3 and No. 4 in Table 2). When we used TSMA monomers, a nanoprotrusion structure-coated layer was observed on the surface of the slide glass following plasma polymerization, as shown in Nos. 3 and 4 in Table 2. These nanoprotrusion structures contribute to the superhydrophobic properties of the specimens. 
$110.0^{\circ}$

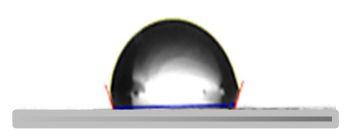

No. 1

$115.0^{\circ}$

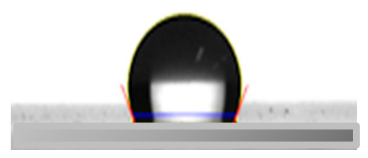

No. 4 $153.0^{\circ}$

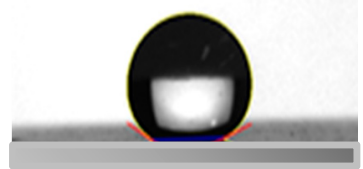

No. 2 $123.0^{\circ}$

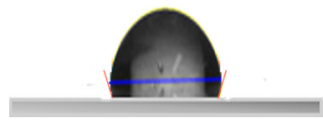

No. 3

$95.0^{\circ}$

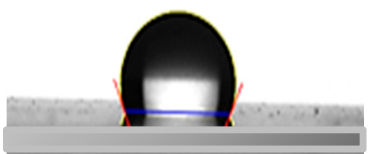

No. 5

Figure 8. Water contact angles of slide glass surfaces plasma-coated with poly(TSMA-co-MMA).
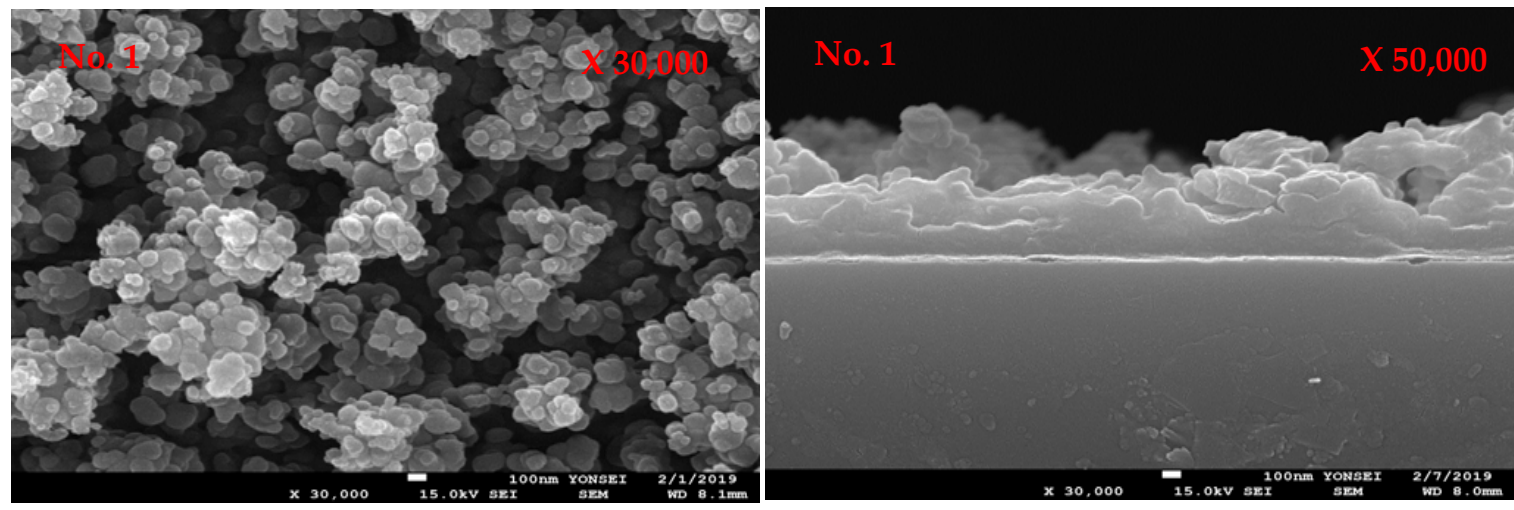

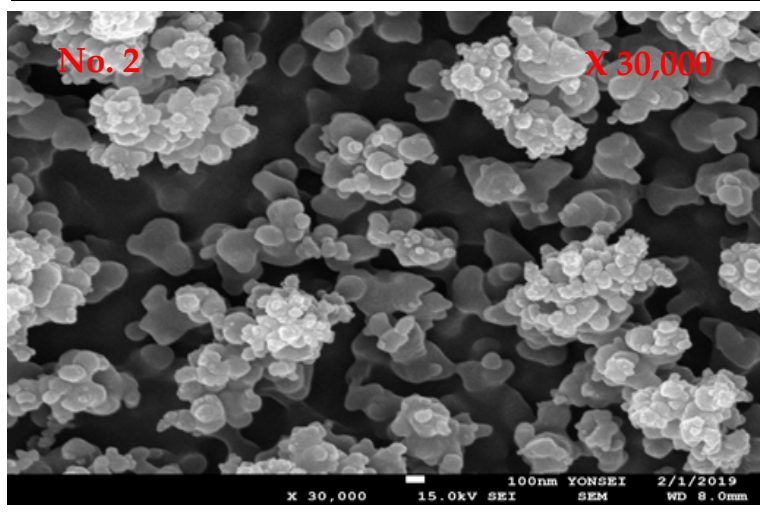

Surface

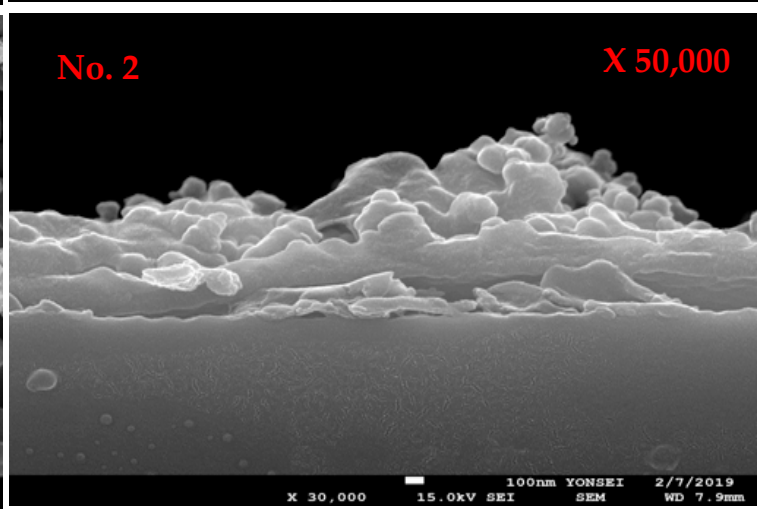

Side face

Figure 9. SEM images of glass surfaces and side faces plasma-coated with poly(TSMA-co-MMA) (No. 1 and 2 in Table 2).

Figure 11 displays SEM images of the plasma-coated glass surface and side face of poly(TSMA-co-MMA), No. 5 in Table 2. Small nanoprotrusions were observed on the surface of the slide glass and side face, which is attributable to the poly(TSMA-co-MMA) polymer film, as shown in the picture. When a large amount of MMA was added to the feed solution, the coated poly(TSMA-co-MMA) formed a flat film, as shown in No. 5 in Figure 9, due to the poly(MMA). These results suggest that poly(TSMA) contributed to the nanoparticle structure and poly(MMA) made the nanofilm structure. 

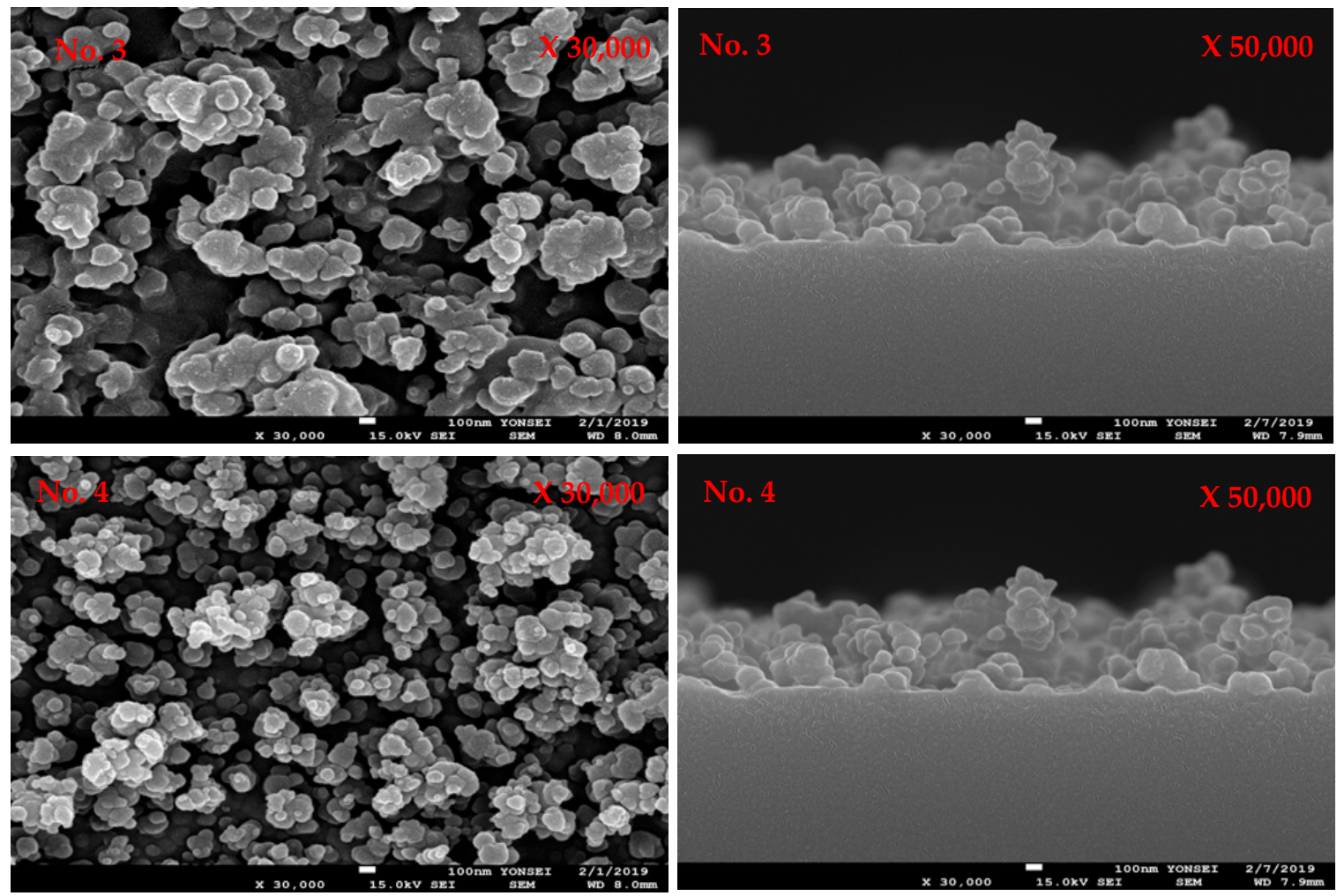

Surface

Side face

Figure 10. SEM images of glass surfaces and side faces plasma-coated with poly(TSMA-co-MMA) (Nos. 3 and 4 in Table 2).
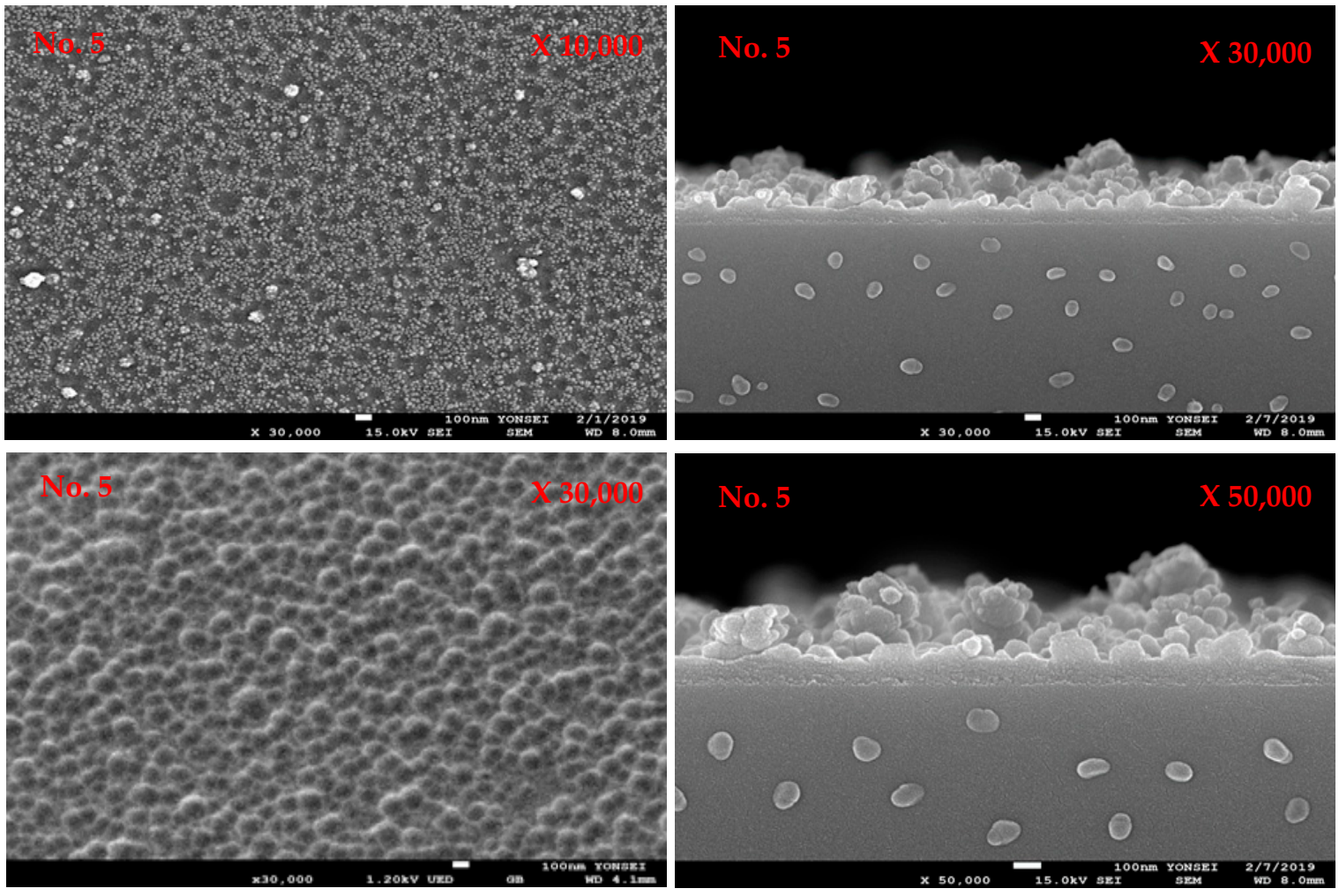

Surface

Side face

Figure 11. SEM images of glass surfaces and side faces plasma-coated with poly(TSMA-co-MMA) (No. 5 in Table 2). 
Figure 12 displays the XPS spectra of the slide glass surface with poly(TSMA-coMMA), No. 2 in Table 2, prepared by plasma polymerization. $\mathrm{Si}_{2 \mathrm{p}}$ and $\mathrm{Si}_{2 \mathrm{~s}}$ peaks were seen at binding energies of $100 \mathrm{eV}$ and $150 \mathrm{eV}$ due to poly(TSMA) prepared by plasma polymerization. These results show that we are able to make a poly(TSMA-co-MMA) coating with a nanoprotrusion structure by plasma polymerization.

\begin{tabular}{cc}
\hline Name & Atomic \% \\
\hline C1s & 30.59 \\
O1s & 44.93 \\
Si2p & 24.48 \\
\hline
\end{tabular}

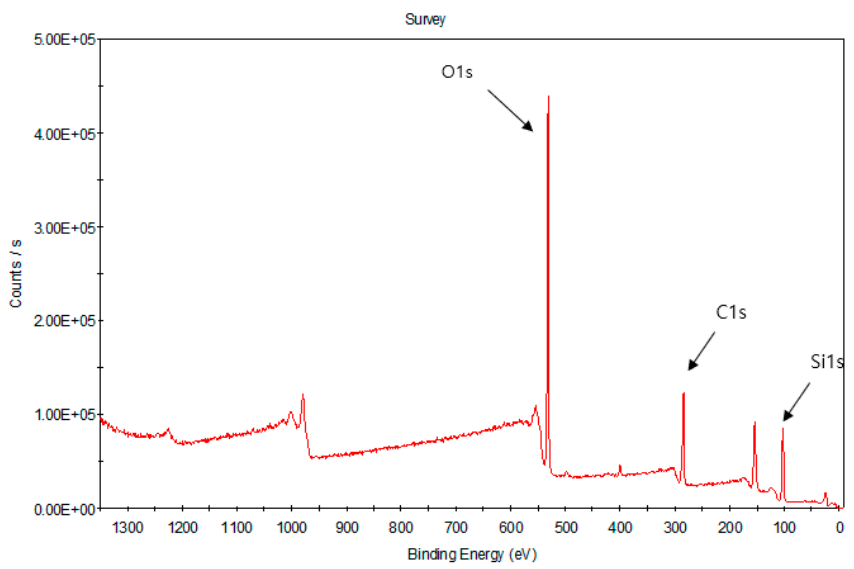

Figure 12. XPS spectra of a glass slide surface plasma-coated with poly(TSMA-co-MMA) (No. 2 in Table 2).

\section{Discussion}

Figure 13 illustrates the plasma process by which poly(TSMA-co-MMA) is coated on a glass surface. When vinyl monomers with TSMA and MMA were inserted into the plasma flame, activated monomers with free radicals were generated $[12,14]$, and chain-growth polymerization occurred in the plasma flame; these chains of polymers then dropped onto the surface of the glass, as shown in Figure 13. Polymeric nanoparticles were generated using TSMA vinyl monomers through the plasma process, and polymeric films were produced using MMA vinyl monomers in the plasma process. Polymeric nanoprotrusions were also synthesized using mixtures of TSMA and MMA monomers and a cold plasma process, as shown in Figure 13.

in Plasma

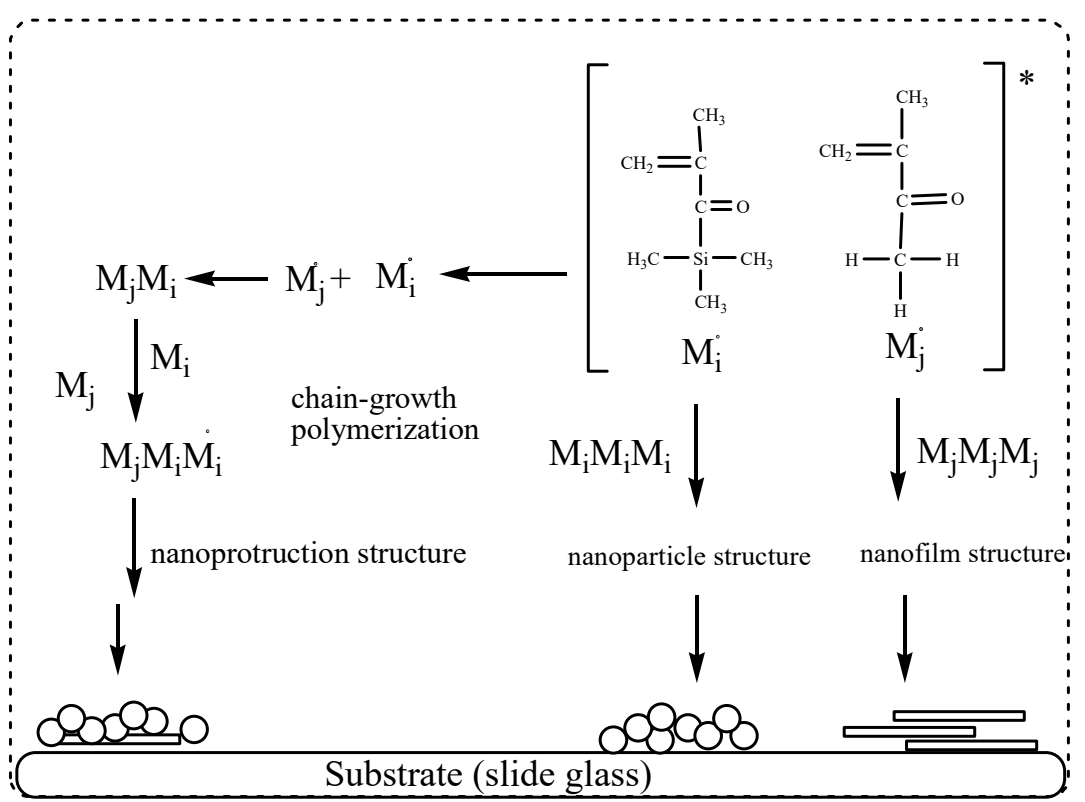

Figure 13. Schematic illustration of plasma coating of poly(TSMA-co-MMA) on a glass surface. 


\section{Conclusions}

In order to create superhydrophobic coatings, vinyl polymer coatings were formed on the surface of glass slides through a plasma process. Functional vinyl monomers, such as TFMA, TSMA and MMA, that contain side groups with symmetrical polarity, were used. The vinyl polymer-coated slide glass was analyzed via water contact angle measurement, SEM, XPS and transmittance to assess their superhydrophobicity. Given these results, we can draw the following conclusions.

(1) Polymeric nanoparticles can be coated onto the surface of slide glass using TSMA through a plasma process.

(2) Polymeric nanofilms can be coated onto the surface of slide glass using TFMA, MMA and a mixture of TFMA and MMA.

(3) Polymeric nanoprotrusions can be deposited onto the surface of slide glass using a mixture of TSMA and MMA through a plasma process.

(4) The relative magnitude of the hydrophobic properties produced are as follows. Polymeric nanoprotrusions $>$ polymeric nanoparticles $>$ polymeric nanofilm.

(5) Superhydrophobicity ( $153^{\circ}$ contact angle) was obtained on the poly(TSMA/MMA) (80/20, mol-\%)-coated slide glass surface.

(6) The transmittance (\%) in the UV, IR, and VL regions was very high.

Author Contributions: S.-W.Y. conducted an experiment for this study. I.-K.Y. built and supplemented the plasma device for this study. W.-J.K. established an overall analysis method for this study and conducted an analysis of the results. S.-H.C. created the synthesis method and research plan for this study. All authors contributed to the article and approved the submitted version. All authors have read and agreed to the published version of the manuscript.

Funding: This work was supported by the National Research Foundation of Korea (NRF-2020R1F1A1074571) and the Korean Innovation Foundation (2020-DD-RD-0124-01-201) and R\&D Program 'Plasma Convergence \& Fundamental Research' through the Korea Institute of Fusion Energy (KFE) funded by the Government funds.

Institutional Review Board Statement: Not applicable.

Informed Consent Statement: Not applicable.

Data Availability Statement: Not applicable.

Conflicts of Interest: The authors declare no conflict of interest. That is, The authors declare that the research was conducted in the absence of any commercial or financial relationships that could be construed as a potential conflict of interest.

\section{References}

1. Hou, J.; Zhang, H.; Yang, Q.; Li, M.; Song, Y.; Jiang, L. Bio-inspired photonic-crystal microchip for fluorescent ultratrace detection. Angew. Chem. Int. Ed. Engl. 2014, 53, 5791-5795. [CrossRef] [PubMed]

2. Huang, Y.; Zhou, J.; Su, B.; Shi, L.; Wang, J.; Chen, S.; Wang, L.; Zi, J.; Song, Y.; Jiang, L. Colloidal photonic crystals with narrow stopbands assembled from low-adhesive superhydrophobic substrates. J. Am. Chem. Soc. 2012, 134, 17053-17058. [CrossRef] [PubMed]

3. Li, H.; Wang, J.; Yang, L.; Song, Y. Superoleophilic and superhydrophobic inverse opals for oil sensors. Adv. Funct. Mater. 2008, 18, 3258-3264. [CrossRef]

4. Shen, W.; Li, M.; Ye, C.; Jiang, L.; Song, Y. Direct-writing colloidal photonic crystal microfluidic chips by inkjet printing for label-free protein detection. Lab Chip 2012, 12, 3089-3095. [CrossRef] [PubMed]

5. Tian, D.; Song, Y.; Jiang, L. Patterning of controllable surface wettability for printing techniques. Chem. Soc. Rev. 2013, 42, 5184-5209. [CrossRef] [PubMed]

6. Wang, J.; Zhang, Y.; Wang, S.; Song, Y.; Jiang, L. Bioinspired colloidal photonic crystals with controllable wettability. Acc. Chem. Res. 2011, 44, 405-415. [CrossRef] [PubMed]

7. Xue, Z.; Wang, S.; Lin, L.; Chen, L.; Liu, M.; Feng, L.; Jiang, L. A novel superhydrophilic and underwater superoleophobic hydrogel-coated mesh for oil/water separation. Adv. Mater. 2011, 23, 4270-4273. [CrossRef] [PubMed]

8. Zhang, Z.; Zhang, X.; Xin, Z.; Deng, M.; Wen, Y.; Song, Y. Controlled inkjetting of a conductive pattern of silver nanoparticles based on the coffee-ring effect. Adv. Mater. 2013, 25, 6714-6718. [CrossRef] [PubMed] 
9. Ben Salem, D.; Carton, O.; Fakhouri, H.; Pulpytel, J.; Arefi-Khonsari, F. Deposition of water stable plasma polymerized acrylic acid/MBA organic coatings by atmospheric pressure air plasma jet. Plasma Process. Polym. 2014, 11, 269-278. [CrossRef]

10. Biederman, H.; Slavínská, D. Plasma polymer films and their future prospects. Surf. Coat. Technol. 2000, 125, 371-376. [CrossRef]

11. Friedrich, J. Mechanisms of plasma polymerization-Reviewed from a chemical point of view. Plasma Process. Polym. 2011, 8, 783-802. [CrossRef]

12. Bui, Q.-T.; Yu, I.-K.; Gopalan, A.I.; Saianand, G.; Kim, W.; Choi, S.-H. Facile fabrication of metal oxide based catalytic electrodes by AC plasma deposition and electrochemical detection of hydrogen peroxide. Catalysts 2019, 9, 888. [CrossRef]

13. Wang, X.; Cho, Y.H.; Kawakam, Y. Improvement of the performance of transmission holographic grating by hydrolysis-induced change of the property of polymer matrix. Polym. J. 2008, 40, 601-606. [CrossRef]

14. Jeon, J.-S.; Yu, I.-K.; Kim, W.; Choi, S.-H. Electrocatalytic oxidation of methanol by a polymeric Ni complex-modified electrode prepared by a one-step cold-plasma process. Front. Chem. 2020, 8, 595616. [CrossRef] [PubMed] 